\title{
EFEITO DO TEMPO DE EXPOSIÇÃO À IRRADIAÇÃO GAMA NA VIABILIDADE DE CÉLULAS-TRONCO MESENQUIMAIS
}

\author{
T. T. GOMES', W. D. C. GAIÃO'2, J. P. AGUIAR², T. Q. FAUSTINO², T. S. \\ FERNANDES ${ }^{2}$, \\ C. G. RODRIGUES 2 , P. L. MEDEIROS ${ }^{3}$, M. B. SILVA², E. B. da SILVA ${ }^{4}$, \\ M. BRAYNER CAVALCANTI ${ }^{1}$
}

\author{
${ }^{1}$ Universidade Federal de Pernambuco, Centro de Tecnologia e Geociências, Departamento \\ Energia Nuclear \\ ${ }^{2}$ UniversidadeFederal de Pernambuco, Centro de Biociências, Departamento de Biofísica e \\ Radiobiologia \\ ${ }^{3}$ Universidade Federal de Pernambuco, Departamento de Histologia e Embriologia \\ ${ }^{4}$ UniversidadeFederal de Pernambuco, Centro Acadêmico de Vitória
}

\section{E-mail para contato: thaaty_gomes@hotmail.com}

RESUMO - As células tronco-mesenquimais (CTMs) são classificadas como células indiferenciadas que são capazes de se diferenciar em tipos celulares especializados, contudo essas células não apresentam uma sensibilidade à radiação prevista pela lei de radiossensibilidade. Ao longo dos últimos anos, diversas pesquisas têm mostrado que essas células são resistentes a altas doses de radiação, mantendo seu DNA integro e a sua capacidade de diferenciação nas linhagens osteogênica, condrogênica $e$ adipogênica. No entanto, há poucos trabalhos na literatura comparando tempos diferentes de irradiação de CTMs. Sendo assim, no presente trabalho avaliou-se a viabilidade celular pelo teste do MTT de CTMs irradiadas in vitro de forma aguda e prolongada e cultivadas por tempos diferentes tempos após a irradiação. Os resultados indicam influência do tempo de irradiação das CTMs apenas no primeiro, segundo e oitavo dia de incubação, e que a viabilidade celular das amostras irradiadas reduz com o passar do tempo para ambas as condições de irradiação, a partir do segundo dia de cultivo.

Palavras-chave: Células-tronco Mesenquimais, Radiação Ionizante, Sobrevivência Celular

\begin{abstract}
The mesenchymal stem cells (MSC) are classified as undifferentiated cells that are able to differentiate in specialized cell types, therefore these cells do not present a sensitivity to radiation as predicted by the law of radiosensitivity. In the past few years, researches have shown that these cells are resistant to high doses of radiation, maintaining their DNA intact and their ability to differentiate into osteogenic, chondrogenic and adipogeniclines. However, there are few studies in the literature comparing different times of irradiation of MSC. Thus, the present study aimed to differentiate, by MTT assay, whether there are differences in the cellular viability response when the samples are in vitro irradiated in an acute and protracted manner.
\end{abstract}


The results indicate that there was influence of the irradiation time of samples only in the first, second and eight day of cell culture, and that the cell viabibility of irradiated samples decreases with time for both irradiation conditions, from the second day of culture.

Keywords: Mesenchymal Stem Cells, Ionizing Radiation, Cell Survival

\section{INTRODUÇÃO}

A interação da radiação ionizante (RI) com a matéria viva pode acarretar diversos tipos de danos biológicos. No entanto, a intensidade destes danos pode variar de acordo com fatores físicos, químicos e biológicos. A taxa de dose absorvida, definida como a energia média depositada pela radiação em um volume elementar de matéria de massa $(\mathrm{dm})$, por unidade de tempo, é um parâmetro físico importante na avaliação de danos biológicos (CNEN 3.01). Quando a exposição é à baixa taxa de dose, o dano produzido em uma fita do DNA pode ser reparado antes que a próxima fita sofra colisão com outros feixes de radiação, minimizando o somatório de danos (HALL \& GIACCIA 2006; IAEA, 2011).

Os fatores biológicos também são importantes, já que cada indivíduo ou tipo celular possui características distintas que influenciam na sua radiossensibilidade. Já é bem estabelecido na Radiobiologia que tecidos jovens são mais sensíveis aos danos radioinduzidos, porém a Comissão Internacional de Proteção Radiológica (International Commissionon Radiological Protection - ICRP), em seu relatório sobre a "Biologia das Células-Tronco com Respeito aos Aspectos Carcinogênicos para Proteção Radiológica", recomenda intensificar os estudos para melhor compreender a sensibilidade das célulastronco às radiações ionizantes e os mecanismos mutacionais, tanto em exposições com alta quanto com baixa taxa de dose (ICRP, 2015).

Portanto, o objetivo do presente trabalho foi avaliar a viabilidade de células-tronco mesenquimais irradiadas com baixa e alta taxa de dose.

\section{MATERIAIS E MÉTODOS}

\subsection{Coleta, isolamento e cultivo das células-tronco mesenquimais}

As células-tronco mesenquimais (CTMs) foram obtidas a partir de cordão umbilical humano, coletado após a aprovação do Comitê de Ética em Pesquisa em Seres Humanos do Centro de Ciências da Saúde da Universidade Federal de Pernambuco sob parecer de número 2.259.272 (CAAE: 67002117.0.0000.5208). A coleta foi realizada no Hospital de Ávila (Recife, PE) após parto cesáreo.

Os cordões foram coletados em um recipiente estéril contendo solução salina em EDTA $(2 \mathrm{mM})$, antibióticos - penicilina $(150 \mathrm{U} / \mathrm{ml})$, estreptomicina $(150 \mu \mathrm{g} / \mathrm{mL})$ e anfotericina $(5 \mathrm{mg} / \mathrm{ml})$, sendo processados no período de até 6 horas pós-parto. $\mathrm{O}$ processamento do cordão e obtenção das células foi realizado de acordo com a técnica da migração espontânea (ISHIGE et al., 2009). O cordão foi cortado em fragmentos de aproximadamente $2 \mathrm{~cm}$; as duas artérias e a veia foram removidas cirurgicamente, para a obtenção apenas das células da geleia de Wharton. 
As CTMs foram mantidas em garrafas de cultura com Low DMEM (Gibco) suplementado com soro fetal bovino (SFB, LGC Biotecnologia), fator de crescimento (F12, Gibco) e antibióticos (penicilina e estreptomicina) em incubadora a $37^{\circ} \mathrm{C}, 80 \%$ de umidade e $5 \%$ de $\mathrm{CO}_{2}$. As células foram encaminhadas para irradiação quando estavam na segunda passagem.

\subsection{Irradiação das amostras}

As CTMs foram irradiadas com dose de 3 Gy de raios gama oriunda de duas fontes de cobalto-60: de baixa taxa de dose (Cobalt Irradiator Radionics Laboratory) e de alta taxa de dose (Gammacell 220 Excel). Uma garrafa contendo CTMs não foi irradiada, servindo como o controle. As amostras foram agrupadas conforme os dados demonstrados na Tabela 1.

Tabela 1- Desenho experimental para irradiação das amostras de CTMs. Os parâmetros de taxa de dose, tempo de exposição e temperatura estão descritos para cada um dos grupos.

\begin{tabular}{cccc}
\hline Grupos & Taxa de & $\begin{array}{c}\text { Tempo de } \\
\text { Exposição }\end{array}$ & $\begin{array}{c}\text { Temperatura }\left({ }^{0} \mathrm{C}\right) \\
\text { Mínima e Máxima }\end{array}$ \\
\hline Baixa Taxa Dose (BT) & $1,653 \mathrm{~Gy} / \mathrm{h}$ & $1 \mathrm{~h} 48 \mathrm{~min} 55 \mathrm{~s}$ & $22,3-26,8$ \\
\hline Alta Taxa Dose (AT) & $2,181 \mathrm{kGy} / \mathrm{h}$ & $0,436 \mathrm{~s}$ & 37 \\
\hline
\end{tabular}

\subsection{Análise da morfologia}

A análise da morfologia das CTMs foi realizada em todos os tempos de cultivo celular com auxílio de um microscópio óptico invertido com contraste de fase (LEICA), com aumento de 10X. Para todos os tempos de cultivo celular, foram obtidas fotomicrografias.

\subsection{Teste de Citotoxicidade}

O teste de citotoxicidade foi realizado com MTT (3-(4,5-dimetiltiazol-2il)-2,5difenil brometo de tetrazolina). As células foram distribuídas em placas de 96 poços com uma concentração de $1 \times 10^{4}$ célula/poço. As placas foram mantidas na estufa nas mesmas condições de cultura, durante 1, 2, 3, 4, 8 e 16 dias. Após cada período, foram adicionados $20 \mu \mathrm{L}$ do MTT ( $5 \mathrm{mg} / \mathrm{mL})$, e a placa foi incubada por mais 4 horas. Para solubilização dos cristais de formazan, foram adicionados $100 \mu \mathrm{L}$ de DMSO. Para os "brancos" foi utilizado poços com DMSO. As leituras foram realizadas em espectrofotômetro em 595 nm (Varioskan Flash, ThermoScientific).

\subsection{Análise Estatística}

Utilizou-se o teste de Wilcoxon a um nível de significância de 5\%. 


\section{RESULTADOS E DISCUSSÃO}

As alterações na morfologia celular podem ser utilizadas como indicativos de danos radioinduzidos (IAEA, 1997). As CTMs, quando isoladas através do método de migração espontânea, aderem às garrafas plásticas, formando monocamadas entre 15 e 21 dias (MITCHELL et al., 2003; ISHIGE et al., 2009). Na Figura 1, são mostradas fotomicrografias de células-tronco mesenquimais não irradiadas (controle) e irradiadas com baixa (BT) e alta taxa de dose (AT), com 1, 4 e 16 dias de cultivo.

Figura 1 - Fotomicrografias de células-tronco mesenquimais.

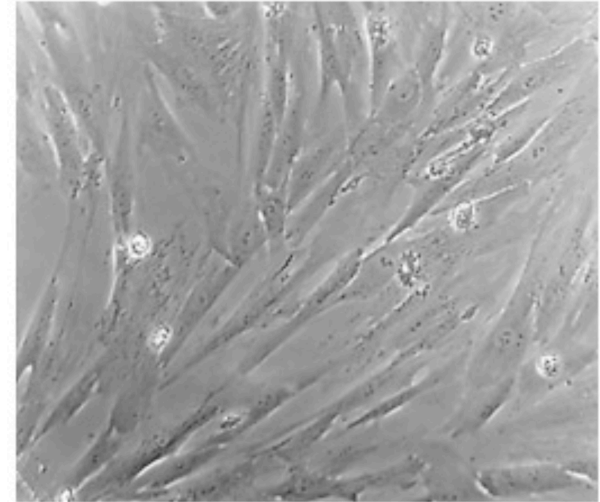

CONTROLE

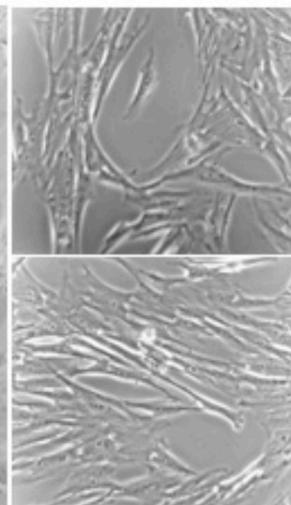

DIA 1

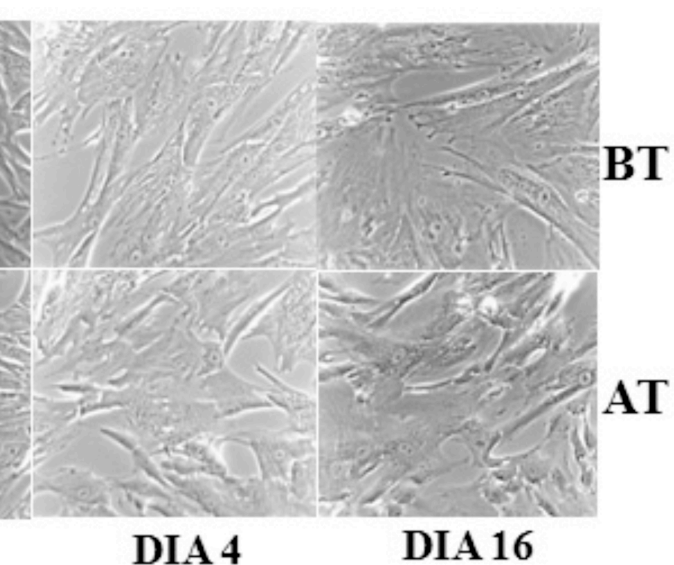

DIA 4
DIA 16

Conforme apresentado nas fotos acima, as CTMs controle (não irradiadas) apresentaram uma morfologia fibroblastóide, alongadas e com um único núcleo, estando de acordo com a morfologia já descrita na literatura (CHEN et al., 2015). No $1^{\circ}$ dia após a irradiação, as CTMs se apresentam mais espaçadas, não apresentando alteração na sua morfologia. No $4^{\circ}$ e $16^{\circ}$ dias de cultura, as CTMs irradiadas, com ambas as taxas de dose, tiveram sua morfologia modificada, apresentando-se com um aspecto rendilhado e em um arranjo com mais espaçamento. Nicolay e colaboradores (2013) observaram um aumento do tamanho das CTMs e uma redução da taxa de mitose, após uma exposição com $10 \mathrm{~Gy}$. Assim como nossos resultados, estes mesmos autores também não encontraram nenhuma indicação de apoptose por meio da análise morfológica.

A Figura 2 apresenta o percentual médio da viabilidade das células-tronco mesenquimais controle (não irradiada) e das irradiadas com baixa taxa (BT) e com alta taxa (AT). 
Figura 2- Percentual médio da viabilidade celular.

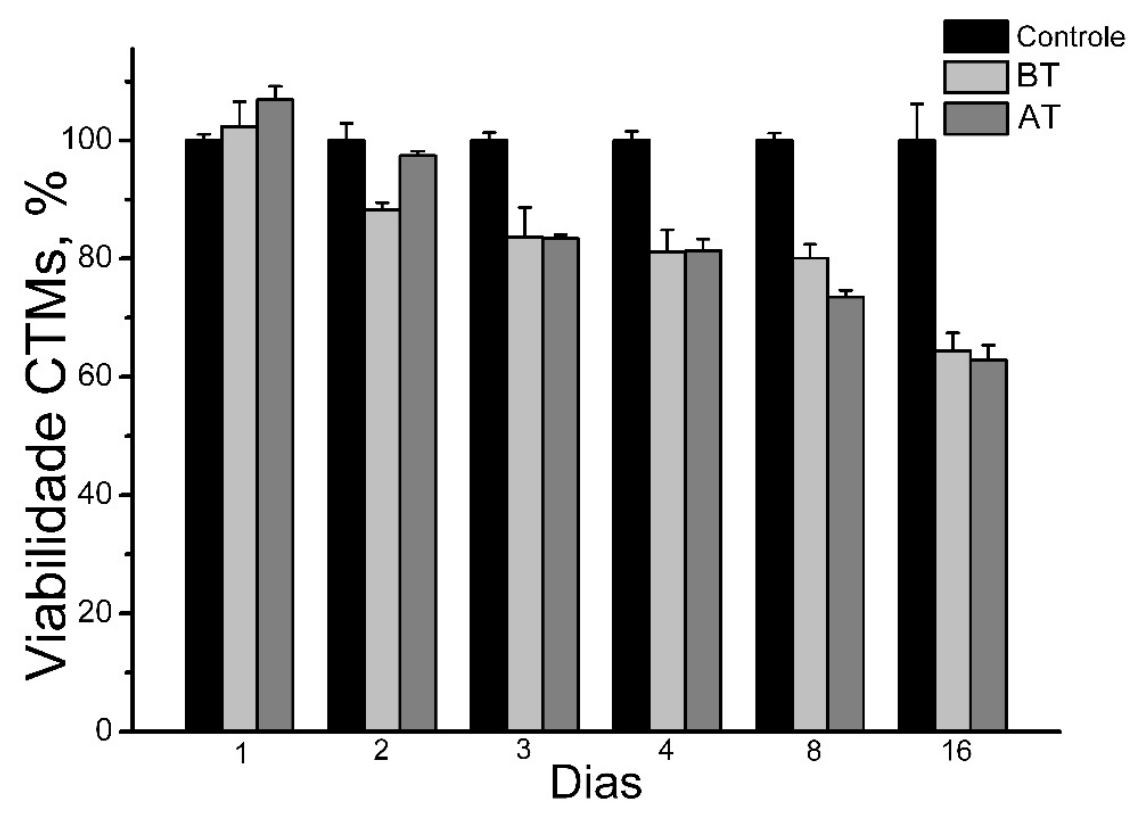

As médias percentuais das viabilidades das células controle (não irradiadas) foram normalizadas para $100 \%$ para todos os tempos de cultivo celular. Já para as amostras irradiadas com baixa taxa de dose e incubadas por 1, 2, 3, 4, 8 e 16 dias as médias percentuais das viabilidades das CTMs foram de $102,0 \% \pm 4,2 ; 88,3 \% \pm 1,2 ; 83,7 \% \pm 5 ; 81,1 \% \pm 3,7$; $80,0 \% \pm 2,4 ; 64,4 \% \pm 3,0$, respectivamente. Já as CTMs irradiadas com alta taxa de dose, as médias percentuais das viabilidades foram de $106,9 \% \pm 2,3 ; 97,4 \% \pm 0,7 ; 83,4 \% \pm 0,7 ; 81,3 \%$ $\pm 2,0 ; 73,5 \% \pm 1,1$ e $62,8 \% \pm 2,5$, respectivamente.

Ao comparar as viabilidades das CTMs controle (não irradiadas) com as CTMs irradiadas em BT e AT, observa-se uma diferença estatisticamente significativa $(p<0,05)$ das viabilidades das CTMs irradiadas para todos os tempos de incubação. No entanto, só é possível observar uma diferença das viabilidades das CTMs entre as amostras irradiadas com AT e BT no primeiro, segundo e no oitavo dia de incubação. Embora estudos relatem que as CTMs não apresentam um aumento dos níveis de apoptose após a exposição à altas doses de RI (NICOLAY et al., 2013), a dose de $3 \mathrm{~Gy}$, utilizada nesta pesquisa, ocasionou uma diminuição da viabilidade das CTMs após $2^{\circ}, 3^{\circ}, 4^{\circ}, 8^{\circ}$ e $16^{\circ}$ dias de cultivo celular, independentemente da taxa de dose empregada.

Os efeitos da taxa de dose são reconhecidos como fatores físicos da radiação que podem contribuir no surgimento de efeitos adversos associados à exposição. Na radiobiologia, tanto a dose da radiação quanto a taxa de dose têm um papel importante na formação dos danos biológicos. Portanto, a taxa de dose reflete a maneira como os danos sub-letais são distribuídos e reparados após a exposição à RI (FALCÃO et a., 2015).

Nesse estudo é possível observar uma diminuição estatisticamente significativa $(\mathrm{p}<0,05)$ das viabilidades das CTMs irradiadas com AT no oitavo dia, quando compradas com das CTMs irradiadas com BT. Embora na literatura seja descrito que células irradiadas com alta taxa de dose sobrevivam menos do que as células irradiadas com baixa taxa de dose, para o mesmo valor de dose absorvida total, verificamos que para o $1^{\circ}$ e $2^{\circ}$ dia de cultivo, as CTMs irradiadas com AT apresentaram maior viabilidade celular $(\mathrm{p}<0,05)$. 
Não houve uma conformidade entre os resultados comparativos de BT e AT para todos os tempos de cultura. Provavelmente, isso se deve a vários parâmetros que podem ter influenciado nos dados, tais como: 1- o tempo de exposição à radiação (1 h 48 min e $55 \mathrm{~s}$ ) não foi suficiente para que ocorresse o reparo da quebra da dupla fita do DNA (de aproximadamente $2 \mathrm{~h}$ ) (IAEA, 2011). 2- as temperaturas no momento da irradiação foram diferentes entre BT e AT, sendo menor que a temperatura fisiológica $\left(37^{\circ} \mathrm{C}\right)$ para $\mathrm{BT}$, o que pode gerar um efeito combinado de temperatura e irradiação para este grupo (FERNANDES et al., 2016).

Para as amostras irradiadas, verifica-se uma diminuição estatisticamente significativa $(\mathrm{p}<0,05)$ das viabilidades das CTMs entre os tempos de cultivo de 1 para 2 dias, de 2 para 3 dias, de 4 para 8 dias e de 8 para 16 dias, independente da taxa de dose. Isso se deve ao fato de que com o passar do tempo, os danos radioinduzidos são manifestados durante a proliferação celular, levando às células a ativar os mecanismos de apoptose ou de reparo celular, a depender da quantidade de dano. A diminuição da sobrevivência celular com o passar do tempo de cultivo indica a cinética de sinalização do dano celular e da indução da morte celular, que não é algo imediato após irradiação, mas que requer um tempo necessário para que a cascata de eventos envolvidos com a morte celular. Estes dados sugerem que, ao se avaliar sobrevivência celular após a exposição às radiações ionizantes, um tempo mínimo de 2 dias faz-se necessário para começar a visualizar os efeitos radioinduzidos. Mais estudos são necessários para caracterizar o padrão de resposta das células-tronco mesenquimais às altas e baixas taxas doses de radiação ionizante.

\section{CONCLUSÃO}

Há diminuição não imediata da sobrevivência de células-tronco mesenquimais quando expostas à dose de $3 \mathrm{~Gy}$, detectável a partir do segundo dia de cultivo celular. A sobrevivências destas células diminuíram com o passar do tempo, o que indica uma cinética de sinalização de dano e morte celular. Não houve diferenças de sobrevivências entre as taxas (BT e AT), exceto para os dois primeiros dias e oitavo dia. No primeiro e segundo dia, houve aumento da sobrevivência em AT, isso provavelmente se deve a outros fatores que podem ter influenciado, tal como a temperatura de irradiação das amostras e do tempo médio de reparo de duplas quebras do DNA.

\section{REFERÊNCIAS}

CHEN, G.; YUE, A.; RUAN, Z.; YIN, Y.;WANG, R.; REN, Y.;ZHU L. Comparison of biological characteristics of mesenchymal stem cells derived from maternal-origin placenta and Wharton's jelly.StemCell Res Ther. 2015; 6: 228.

CNEN NN 3.01 - Diretrizes Básicas de Proteção Radiológica. Norma da Comissão Nacional de Energia Nuclear .CNEN NN 3.01 Resolução 164/14 Março / 2014.

FALCÃO, PL.; MOTTA, BM.; LIMA FC.; LIMA CV.; CAMPO TPR. Enhancement of viability of radiosensitive (PBMC) and resistant (MDA-MB-231) clones in low-dose-rate cobalt-60 radiation therapy.Radiol Bras. 2015 Mai/Jun;48(3):158-165.

FERNANDES, TS; LEONCIO SR; XAVIER, ASI.; BRAYNER CAVALCANTI, M.; AMARAL, A. Influence of Samples Conditioning Temperature on Cytogenetic Dosimetry. Annals of The Brazilian Society of Nuclear Biosciences. p. 78-84, 2016. 
HALL, E andGIACCIA AJ.(2006) Radiobiology for the Radiologist.6rd edition. JB Lippincott, Philadelphia.

IAEA (International Atomic Energy Agency) Effects of Ionizing Radiation nn Blood And Blood Components:A Survey. IAEA 1997.

ICRP, 2015.Stem Cell Biology with Respect to Carcinogenesis Aspects of Radiological Protection.ICRP Publication 131. Ann. ICRP 44(3/4).

ISHIGE, I.; NAGAMURA-INOUE, T.; HONDA MJ.; HARNPRASOPWAT, R.; KIDO, M.; SUGIMOTO, M.; NAKAUCHI, H.; TOJO, A. Comparison of mesenchymal stem cells derived from arterial, venous, and Wharton's jelly explants of human umbilical cord. International. Journal of Hematology, 90(2), p.261-269, 2009.

NICOLAY, NH; SOMMER, E.; LOPEZ, R.; WIRKNER, U.; TRINH, T.; SISOMBA,THS.; DEBUS, J.; HO AD; SAFFRICH, R.; HUBER, PE. Mesenchymal Stem Cells Retain Their Defining Stem Cell Characteristics After Exposure to Ionizing Radiation. Int J RadiatOncolBiol Phys.2013 Dec 1;87(5):1171-8.

VIEIRA, L. L. L. M. Estudo dos canais iônicos nas células-tronco mesenquimais de cordão umbilical humano. V Congresso Brasileiro de Células-Tronco e Terapia Celular. Gramado, Rio Grande do Sul, 2010.

\section{AGRADECIMENTOS}

Fundação de Amparo à Ciência e Tecnologia de Pernambuco. 